NAVA BAR

University of Haifa, Israel

BOSHRA KANJ-SIRHAN

Ministry of Education, Israel

\title{
The 'parents' choice': the recent perceptual changes in special education law in israel and its implementation in the field
}

\begin{abstract}
Nava Bar, Boshra Kanj-Sirhan, The 'parents' choice': the recent perceptual changes in special education law in israel and its implementation in the field. Interdisciplinary Contexts of Special Pedagogy, no. 26, Poznań 2019. Pp. 143-162. Adam Mickiewicz University Press. ISSN 2300-391X. e-ISSN 2658-283X. DOI: https://doi. org/10.14746/ikps.2019.26.07
\end{abstract}

The Israeli educational system is dealing intensively for the last two decades in the assimilation of the inclusion approach of student with special needs (SwSN) in general education. The first part of the article presents the historical development of special education in Israel as a background to the presentation of the new amendment of Special Education Law - Amendment 11 (2018). The current stage of the Eleventh Amendment implementation aims to ensure the inclusion of SwSN in the general education by an allocation of budget for his needs according to a standard assessment of his functioning level, in addition to his disability. The SwSN parents' will decide about their child placement according to the model of "The Parents' Choice", and the student's budget will be transferred to the chosen educational framework according to the "Funding Follows the Child" principle. The second part of the article presents a case study of special education school in Israel for students with intellectual developmental disabilities that gradually assimilate the spirit of the law amendment from both aspects - standard assessment of the students functioning and parental partnership, as part of professional work processes carried out at school in Activities of Daily Living (ADL) field.

KEY WORDS: Special Education, Special Education Law in Israel, Activities of Daily Living (ADL) Assessment, 'Parents' Choice' 


\section{Stages in Special Education Development in Israel}

The Israeli educational system is dealing intensively for the last two decades in a process of assimilation of the inclusion approach of students with special needs (SwSNs) in one educational system with their peers, members of the same age group, and in developing of a continuum of educational frameworks that will enable an appropriate solution for the needs of the diverse population of SwSNs. From the establishment of the State of Israel (1948) until the 1970s, the perception was that the special education school has clear advantages over the general education framework and provides the best treatment to the SwSN. ${ }^{1}$ The guiding concept was of separateness from general education. ${ }^{2}$ The number of special education schools in Israel constantly increased during this period. ${ }^{3}$

In the 1970s, a "normalization" approach developed and placed at the center the right of the individual in the society, including the individual with special needs, to a normal lifestyle. On the light of this approach, the inclusion movement began to grow in Israel that was based upon the humanistic philosophical approach, which emphasizes that SwSN is equal in his rights to the student who is not disabled. Accordingly, the basic right of SwSN is to learn together with his peers, in one educational system. ${ }^{4}$ The proponents of this approach maintained that the inclusion will help the "regular" students to understand that diversity between people exists in our so-

${ }^{1}$ G. Avissar, Ts. Bab, Processes and trends in the planning of the studies in Israel for students with disabilities, Theory and Practice in the Planning of the Studies, 2010, 21.

2 M. Marom, K. Bar-Simon Tov, A. Kron, P. Koren, Inclusion of special needs children in the regular educational system: A review of the literature, The Center for the Research of Social Policy in Israel Press, Jerusalem 2006.

${ }^{3}$ H. Ronen, Inclusion: Issues and disputes, [in:] Inclusiveness: Learners with disabilities in education, eds S. Reiter, Y. Leyser, G. Avissar, AHVA Publishers, Haifa 2007; B. Nirje, The basis and logic of the normalization principle, Australia and New Zealand Journal of Developmental Disabilities, 1985, 11(2).

${ }^{4} \mathrm{G}$. Avissar, Inclusion and accessibility: Curriculum planning and implementation for students with disabilities, Mofet Institute, Tel Aviv 2010; M. Marom et al., Inclusion of special needs children in the regular educational system. 
ciety, when each one has a basic right for presence, for expression, for acceptance. ${ }^{5}$

The adoption of the inclusion approach by the Israeli educational system has been expressed from the 1990s in the gradual process of creation a continuum of educational frameworks that provided adequate and adjusted solutions for the diversity among SwSN, for their needs and development, their quality of life and the achievement of the goals set for their education to the least possible extent. ${ }^{6}$ The continuum of educational frameworks for SwSNs in Israel ranges from the school of special education, the special class in the general school, and inclusion in the regular class - the more separate the framework, the services are given there to the student are more comprehensive.

The recognition of the rights of SwSN was expressed in the legislation of the Special Education Law in Israel on July 12, 1988.7 The spirit and the content of the law protect the rights of the SwSN from age 3 to age 21 who have a variety of needs. The law determined special education as a right. ${ }^{8}$ This entitlement for special education ensured that the SwSNs will enjoy systemic learning-teaching processes alongside a series of treatments and services adjusted to their special needs. Above all, the law determined the preference of the general educational system over the special education system in the placement of $\mathrm{SwSN}^{9}$, assuming that the integration, as much as pos-

${ }^{5}$ Y. Harpaz, Every Student Is a Student with Special Needs (Interview with Prof. Shunit Reiter) Hed Hahinuch (Echo of Education), 2013, 87(6), p. 44.

6 J.B. Crockett, J.M. Kauffman, The least restrictive environment. Lawrence Erlbaum, New Jersey, 1999; P. Howard, The Least Restrictive Environment: How to tell, Journal of Law \& Education, 2004, 33.

7 The Special Education Law, 5748, State of Israel, 1988.

${ }^{8}$ N. Blass, A. Laor, Special education in Israel and the policy of inclusion. The Center for the Research of Social Policy in Israel Press, Jerusalem 2002; D. Neon, M. Milshtein, M. Marom, Integration of children with special needs in the elementary schools: Follow up after the implementation of the 'Book of Inclusion' in the Special Education Law.The Center for the Research of Disabilities and Employment of Special Populations, Jerusalem 2012.

${ }^{9} \mathrm{M}$. Marom et al., Inclusion of special needs children in the regular educational system. 
sible, in general education will prepare him for integration in the society outside of the school. Practically, the students with severe difficulties remained in the special schools ${ }^{10}$, the hours allotted for the inclusion of the SwSNs in the regular classes were few and the teachers in the regular classes did not have the knowledge for coping with children with disabilities. The research study of Reiter, Schanin, and Tirosh (1998) indicated that the teachers did not support the inclusion and preferred the opening of special education classes in their schools. ${ }^{11}$

Following the implementation of the Special Education Law in 1988 and the public discussion, public committees were established for the examination of the Special Education Law implementation. Margalit committee that published its report in $2000^{12}$ determined that there are significant discrimination and inequality in the allocation of budgets, resources and services of special education, especially in the inclusion framework. ${ }^{13}$ While the Special Education Law emphasizes the priority of the placement of SwSNs in the general education ${ }^{14}$, with their transition to general education framework their right to receive budgets as they have got in the special education school was canceled, therefore their chances of development, learning and adaptation were compromised. ${ }^{15}$ Against the background of these developments, in 2002, Amendment 7 (B) was

${ }^{10}$ Margalit Committee, Report of the Committee for the Examination of the Realization of the Ability of Students with Learning Disabilities. Ministry of Education, Culture, and Sport, Department of Special Education, Jerusalem 1997; D. Neon, M. Milshtein, M. Marom, Integration of children with special needs in the elementary schools.

${ }^{11}$ S. Reiter, M. Schanin, E. Tirosh, Israeli elementary school students' and teachers' attitudes towards mainstreaming children with disabilities, Special Services in the Schools, 1998, 13(1/2).

${ }_{12}$ Margalit Committee, Report of the Committee for the Examination of the Implementation of the Special Education Law, Ministry of Education, Jerusalem 2000.

${ }^{13}$ Margalit Committee, Report of the Committee for the Examination of the Implementation of the Special Education Law, p. 30.

14 The Special Education Law, 1988.

${ }^{15}$ Margalit Committee, Report of the Committee for the Examination of the Implementation of the Special Education Law, pp. 47-48. 
added to Special Education Law. ${ }^{16}$ The main point of this amendment is the arrangement of the inclusion implementation of SwSNs in general education and primarily the anchoring of their rights and the services to be provided to them by law. ${ }^{17}$

\section{The Eleventh Amendment of the Special Education Law as a Perceptual Change}

In September 2007, against the background of the inclusion implementation and the continued arguments about inequality and lack of effectiveness in the division of the special education budget, the Minister of Education reached the conclusion that the policy of the care of SwSNs had not been discussed in depth and decided to establish a public committee under the leadership of the retired Supreme Court Justice Dalia Dorner, for the examination of the special education system in Israel.18 The stated purposes of the committee were to examine the Ministry of Education policy regarding the SWSNs care and the manner of the budget allocation for these children. An additional purpose was to determine an action plan and priorities for action in this area. ${ }^{19}$ Most arguments put before the committee focused on the inclusion of SwSNs in general education (like in Margalit Committee in 200020) and in the gap exists between

16 The Special Education Law 5762 (Amendment No. 7), State of Israel, 2002.

${ }_{17} \mathrm{G}$. Avissar, Ts. Bab, Processes and trends in the planning of the studies in Israel for students with disabilities; G. Avissar, A. Moshe, P. Licht, "These are basic democratic values": The perceptions of policy makers in the Ministry of Education with regard to inclusion, [in:] Inclusiveness: From theory to practice, eds S. Reiter, G. Avissar, AHVA Publishers, Haifa, 2013; D. Neon, M. Milshtein, M. Marom, Integration of children with special needs in the elementary schools.

18 Dorner Committee, Report of the Public Committee for the Examination of the Special Education System in Israel, Ministry of Education, Jerusalem 2009, p. 3.

${ }^{19}$ Dorner Committee, Report of the Public Committee, p. 35, pp. 57-59.

${ }^{20}$ Margalit Committee, Report of the Committee for the Examination of the Implementation of the Special Education Law. 
the priority determined by the Special Education Law enacted in $2002^{21}$ for the inclusion of SwSNs in general education, and the low priority and the inappropriate funding given to it by the Ministry of Education.22

The committee indicated in the final report the lack of adequate budget for the inclusion track and reached the conclusion that the existing method of budgeting does not always enables a suitable response to the needs of the SwSN. Thus, it causes discrimination since two children with a similar functioning level obtain a different scope of services because each one of them learns in a different education framework - inclusion in general education or special education framework. ${ }^{23}$ Therefore, the current budgetary method influences the choice of the framework in which the SwSN will study. The committee proposed the "Funding Follows the Child" principle $^{24}$ that is used also in other countries. ${ }^{25}$ The budget allocation for the SwSN will be determined by an "Eligibility Committee" and will be based on a standard measurement. Consequently, the budget allocation will be differential that rely not only on the student's disability, but also on a clear criteria based on an assessment of his functioning level. For this purpose, an assessment tool was constructed for the measurement of the SwSN's observed behaviors in the aspects of behavior and functioning that can be observed during the everyday life ${ }^{26}$ in the educational institution, without the need to hold diagnostic tests for the student. In addition, the committee recommended setting certain groups that are distinct from one another in the degree to which they need special education resources.

21 The Special Education Law, 2002.

22 Dorner Committee, Report of the Public Committee, pp. 35-37.

23 Dorner Committee, Report of the Public Committee, pp. 37-38, p. 53.

24 Dorner Committee, Report of the Public Committee, p. 54, 57.

25 C. Robson, Students with disabilities, learning difficulties and disadvantages: statistics and indicators. OECD: Organisation for Economic Cooperation and Development, France 2005, p. 20. ISBN 9264009809.

${ }^{26}$ Dorner Committee, Report of the Public Committee, p. 58, 73, 76. 
Every group will be allotted the special education services adapted according to a "budgetary key" and every SwSN will be ascribed to one of the groups. ${ }^{27}$

The budget that will be determined for the student will be conveyed to an educational framework, according to "The Parents' Choice" model 28 , whether it is a separate special education framework or inclusion framework - in general education, so that the student's eligibility for professional services will be maintained. This model is already activated in some other countries. ${ }^{29}$ The committee noted that the recognition of the parents' right to be involved in the process of their child's education is recognition of their human rights and is perceived today as essential and vital involvement. The parents are those who can represent their child in the most dedicated manner, and this will encourage them to invest efforts in their child's education and their advancement. ${ }^{30}$ The committee holds that a change in the legal regime, which at its center are the budgeting method of "Funding Follows the Child", according to a standard assessment tool and the SwSN placement based on "The Parents' Choice", will allow the state to provide the resources necessary in a more tailored and just manner, and will enable every SwSN to move between the existing various educational frameworks according to his needs. ${ }^{31}$ This method is considered as enhancing and encouraging the inclusion assimilation. ${ }^{32}$

The recommendations of the Dorner Committee published in 2009 were adopted and anchored in Amendment 11 of the Special

27 Dorner Committee, Report of the Public Committee, p. 58, 76.

${ }_{28}$ Dorner Committee, Report of the Public Committee, p. 53.

29 Students with Disabilities, Learning Difficulties and Disadvantages Policies: Statistics and Indicators. OECD: Organization for Economic Cooperation and Development, 2007, p. 30. ISBN 978-92-64-02762-6.

30 Dorner Committee, Report of the Public Committee, p. 52.

31 Dorner Committee, Report of the Public Committee, p. 54, 58.

32 Students with Disabilities, Learning Difficulties and Disadvantages Policies: Statistics and Indicators, p. 30. 
Education Law that was enacted in 10 July 2018.33 The Ministry of Education started off the implementation in December 2018 in the Northern District of the State of Israel.

\section{Implementation of the Change Spirit in Special Education School: Case Study}

Amendment 11 of the Special Education Law emphasizes the standard assessment of the SwSN functioning as a basis for the determination of his eligibility for special education services. In addition, it emphasizes the parents' choice of their child's placement, a perception that sees the student from a holistic view that places at the center of the educational process not only the student but also his family. The second part of the article will present a process undertaken in an Arab special education school in the northern district of Israel for students with an intellectual developmental disability in low, moderate, and high functioning. The goal of the process is to assimilate gradually the spirit of the law amendment in two mentioned aspects ${ }^{34}$ - a measurable assessment of the students' functioning and the parents' involvement, as a perception, as a language and as a part of the professional work processes in the school. To achieve the goal, the school implemented a process of measurable assessment of the functioning of twelve students from two adult classes in the school, ages 16-21, in the field of activities of daily living (ADL). The students' parents were involved in the assessment findings, in the process of building an individualized educational plan (IEP) for their children in the ADL field, and in the implementation of the plan during the school year. The ADL was

33 The Special Education Law 2734 (Amendment No. 11), State of Israel, 2018.

34 Amendment 11 to the Special Education Law $(2002 ; 2018)$ raises the question of the relevance of the special education school in the new era of the two amendments to the Special Education Law (2002, 2018), which emphasizes the preference of the inclusion in the general education system over separate special education frameworks, as Ronen discussed this before: H. Ronen, The future of the special school, Issues in Special Education and Rehabilitation, 2003, 18(1). 
chosen as the first field of implementation because of its importance to the development of students with an intellectual developmental disability, for their independence and their preparation for integration into society and the workforce..$^{35}$

\section{Measurable Assessment of the Students' Functioning in ADL Field (ADL)}

The assessment tool chosen for the assessment of the two classes' students in the ADL field is a questionnaire developed in 1992 by the World Federation of Occupational Therapists (WFOT) in collaboration with the World Health Organization (WHO) ${ }^{36}$ which translated into Hebrew by Sachs, Yaakobi-Vekert and Zussman. ${ }^{37}$ The questionnaire was adapted to a population of students by Sachs, Schreuer, and Adato-Biram in 2008. ${ }^{38}$ In the examination of the questionnaire reliability after the changes, high reliability was found for the entire questionnaire $(\alpha=.92)$ and for daily instrumental activities $(\alpha=.88) .{ }^{39}$ The questionnaire examines the independence degree in the performance of daily living activities (ADL) and includes assessment of the performance level in twelve basic everyday activities - six basic activities of everyday living (BADL): Transitions (to lying, sitting, standing, standing up...), self-care (brush-

35 The Special Education Law, 1988; 2002; "Assif", a collection kit for the "transition" program for special needs students studying in special education frameworks, ages 16-21, Ministry of Education, Special Education Department, 2012.

${ }^{36}$ Project protocol WHO and WFOT, Quality assurance project concerning CVA- patients, Denmark: The Danish Occupational Therapy Association, 1992.

${ }^{37}$ D. Sachs, R. Yaakobi-Vekert, N. Zussman, A survey of treatment frameworks, methods and assessment methods and treatment which are customary in occupational therapy with patients after a stroke, The Israeli Journal of Occupational Therapy, 1995. H147-H127, 4(4).

${ }^{38}$ D. Sachs, N. Schreuer, I. Adato-Biram, Academic, physical and human support to promote participation of people with disabilities in higher education. Paper presented at the conference of Council of Occupational Therapists in European Countrives (COTEC), Hamburg, Germany (2008, May).

${ }^{39}$ D. Sachs, N. Schreuer, I. Adato-Biram, Academic, physical and human support to promote participation of people with disabilities. 
ing teeth, combing, treating wounds...), dressing, toileting, getting around inside and bathing. In addition, it includes six daily instrumental activities (IADL): preparing meals (coffee, tea, sandwich, preparing a snack...), getting around outside, use of transportation, house maintenance, shopping, and use of public institutions (bank, post office...). The interdisciplinary team of each class ${ }^{40}$ along with the student's parents filled out the questionnaire and indicated the functioning level of every student in each of the twelve activities on a five-point scale: 1 = cannot perform; 2 = needs verbal $/$ physical help or care; $3=$ independent using aids or compensation way, $4=$ performs independently but slowly; and $5=$ performs independently. ${ }^{41}$ As the score is higher, the student is more independent in the everyday activities examined.

\section{The School Work Process Following the Measurable Assessment}

The findings obtained from the measurable assessment of the students' functioning in ADL field were processed on three levels The level of the single student (see figures 1 and 2), the level of the class (see figures 3, 4, 5, and 6) and the level of both classes that took part in the assessment process (see figure 7). The findings were presented in two stages. In the first stage, they were presented to the interdisciplinary staff of each class that began to build an IEP for each student in the ADL field, and a class plan. In the second stage, the findings and the IEP were presented to every student's parents. The parents meeting focused on the way in which the parents can implement parts of the IEP in the family-home framework after the study hours. At the end of the first half of the year, the parents were

${ }^{40}$ The interdisciplinary team of the class includes the homeroom teacher, the subject matter teachers, the school counselor, the paramedical therapists of the class, and in some cases the school psychologist.

${ }^{41}$ D. Sachs, R. Yaakobi-Vekert, N. Zussman, A survey of treatment frameworks, methods and assessment methods. 
partners in the formative assessment process and presented their point of view on their child's functioning in the ADL field in the home framework. The findings obtained in the three levels of processing are as follows:

1. Findings on the individual student level

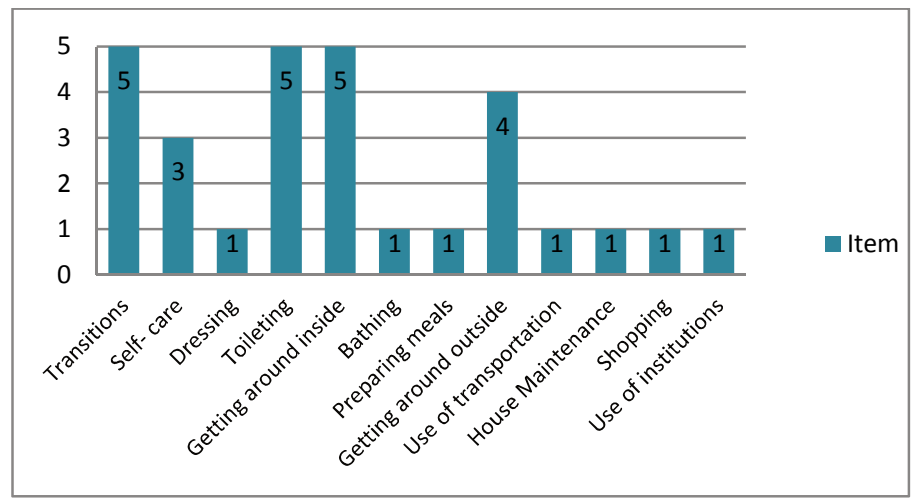

$N=1$; Range: $1-5$

Figure 1. ADL - Assessment of the Individual Student's functioning - Class 1

(Ages 16-19)

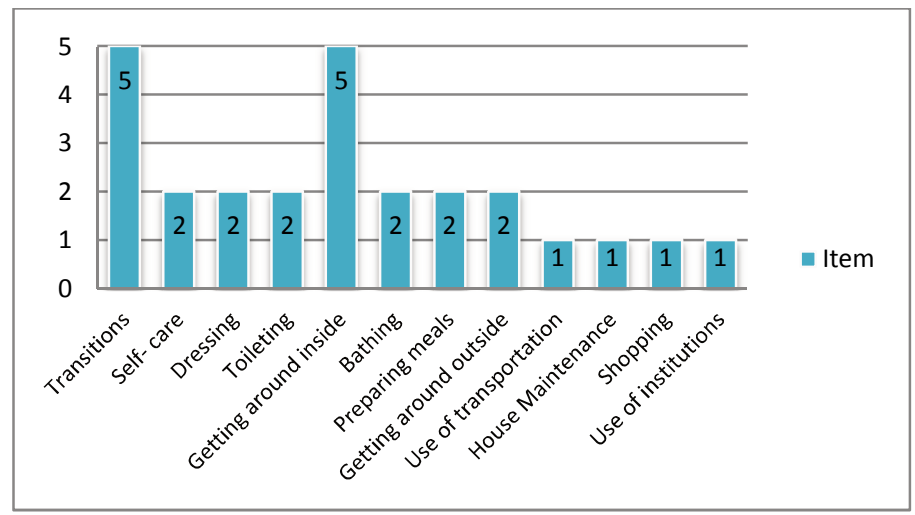

$N=1$; Range: $1-5$

Figure 2. ADL - Assessment of the Individual Student's functioning - Class 2

(Ages 19-21) 
The findings obtained on the individual student level indicate that the different class students function on different levels in the twelve activities of ADL and necessitate the building of a personal work plan tailored to every student in this field.

2. Findings on the class level

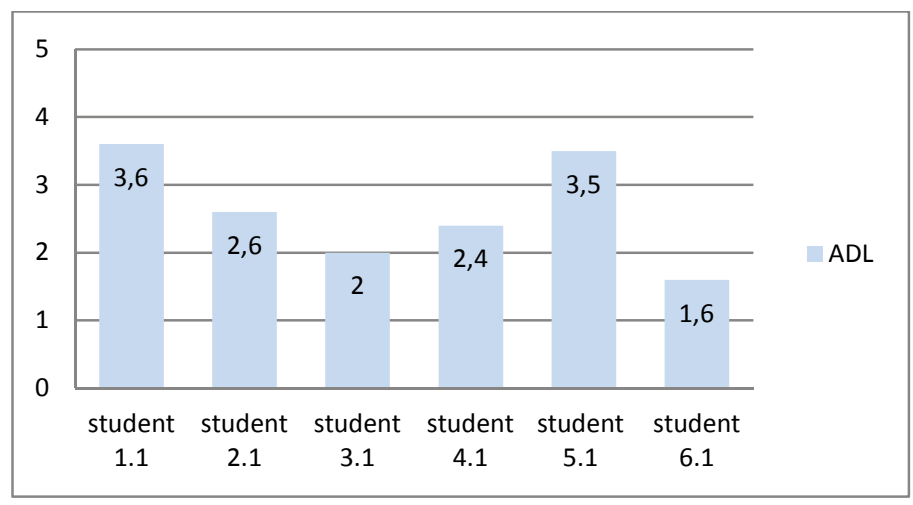

$N=6$; Range: $1-5$

Figure 3. ADL -Assessment Averages of the Students Functioning - Class 1

(Ages 16-19)

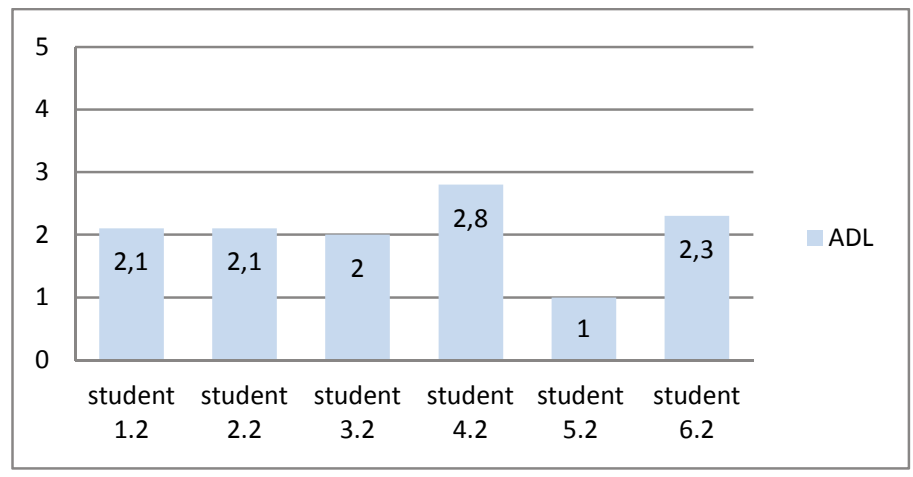

$N=6$; Range: $1-5$

Figure 4. ADL Assessment Averages of the Students Functioning - Class 2

(Ages 19-21) 
The findings on the class level obtained from the functioning assessment of all students in every class indicate the diversity that exists between students of each one of the classes in functioning in the ADL field.

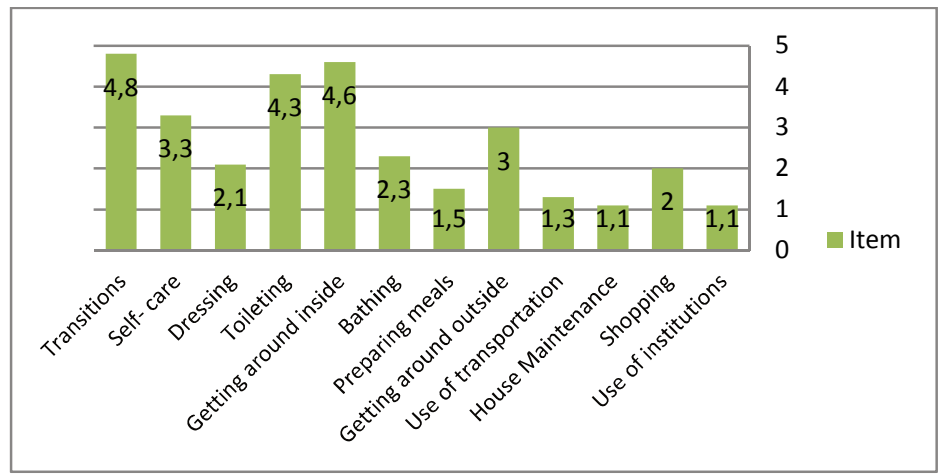

$N=6$; Range: $1-5$

Figure 5. Assessment Averages of Class 1 Students (Ages 16-19) Divided into12 ADL Activities

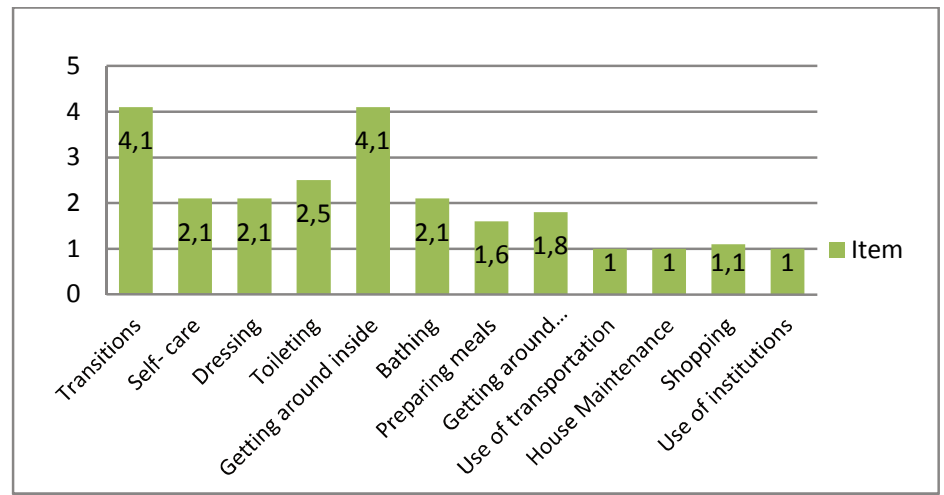

$N=6$; Range: $1-5$

Figure 6. Assessment Averages of Class 2 Students (Ages 19-21) Divided into 12 ADL Activities 
The averages of the students functioning of every class in each one of the 12 ADL activities indicate the diversity that exists in the functioning of the class students in various activities. The picture obtained enables the identification of the activities in which the functioning of all the class students is low or high and therefore enables the building of a tailored class work plan.

3. Findings on the level of the adult students' classes of the school

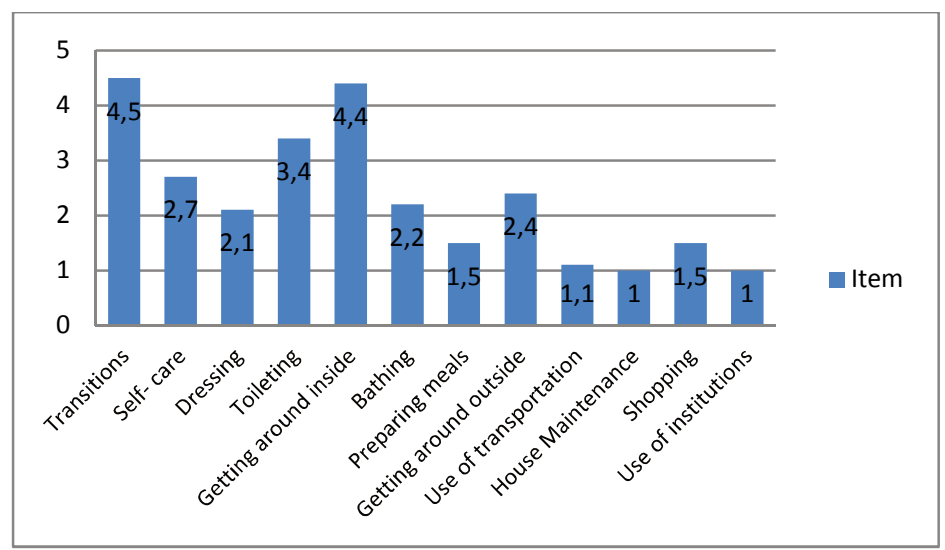

$N=12 ;$ Range: $1-5$

Figure 7. Assessment Averages of the adult students' classes divided into 12 ADL activities

The assessment averages of the adult classes' in each one of the 12 ADL activities indicate the diversity that exists in the students functioning of the two classes in the various activities. The picture obtained enables the identification of the activities in which the functioning of all the adult students is low or high and therefore enables comprehensive overview of the school in the ADL field, writing of a data-based school work plan, setting of objectives for school staff professional development, and the staff instruction in the field of the preparation of students for life. 
To learn and draw conclusions from the process performed on the topic of measurable assessment in the field of ADL in the school and the involvement of the parents in the process, three staff meetings were held during the year under the leadership of the school principal. The staff was asked to provide feedback by answering to reflective questions in four categories: (1) backward-looking - a question aiming at the previous knowledge before the work with the assessment tool; (2) inward-looking - a question aimed at the work process with the assessment tool; (3) outward-looking - a question aimed at the work product of the assessment tool; and (4) forwardlooking - a question aimed at the drawing of conclusions following work with the assessment tool and for future planning. The following paragraph presents an example of a question asked the staff members in each category and an example of an answer given by one of the staff members who took part in the process.

1. Backward-looking: How much did you know about the subject before we started? - "I knew the field of assessment in general, we did assessment processes in the school for students, but the assessment was always based on the impression of the student according to which a verbal assessment was written. Regarding the tool I knew the ADL tool, but this is the first time that we work with it in a computerized, quantitative, and measurable manner. The tool focused our work, and thus the degree of responsibility towards the progress of every student has increased".

2. Inward-looking: What did you learn about yourself while working on measurable assessment subject? - "From the work process in the field of assessment through the ADL tool, I reached a number of insights about myself. First, that I have the ability to work in a team, since the tool requires teamwork, and that I have the ability of interpersonal communication with the staff, the parents, and the students. I was afraid of working with a computerized and measurable tool; only during the work, I have learned how to use it and this strengthened my desire to learn new tools and to be open to changes in assessment ways". 
3. Outward-looking: In what ways did your work meet the standards for this assignment? - "The process that we experienced in the use of measurable assessment tool in the ADL field contributed to the building of a shared professional language that sees the student's needs and simultaneously the needs of the staff, such as professional development in the field of assessment. The use of the tool emphasized the importance of building an individualized plan based on an assessment that involves the parents and recruited me for a shared mission".

4. Forward-looking: What would you like to invest more time on in school? - "I think that it is important to invest more time in building and operating of assessment tools and formative assessment. The use of the tool and the analysis performed indicated that even if two students reached the same average in their total functioning in ADL, this does not indicative of the same function level since it may be that there are differences between them in the various measured activities. Therefore, it is necessary to invest time to review them indepth manner so as to build a tailored program. Moreover, effort must be taken to increase parental involvement in the process since it ensures continuity in the work with the student at home on defined and clear activities. The presentation of the findings on graphs enabled visual and focused feedback for the parents and helped them understanding of the student's needs".

From the answers of the staff members in the four categories, it is possible to learn about the contribution of the process that was performed. The first contribution is the acquisition of a measurable professional tool for the assessment of the SwSNs functioning in one of the important areas of work with students with an intellectual developmental disability - the ADL. Further contributions are the increased responsibility for the students' advancement in light of overt measurable data, the promotion of teamwork and a shared language when the needs of the student are at the center, and the identification of the staff needs for professional development. The process contributed to perceive the parents as partners in the work process with the students, for their advancement and development. 
The staff's openness to changes and the motivation to acquire additional professional assessment tools (instead of fear of these tools that are ascribed by the teachers to professional diagnostic factors) are apparent.

\section{Summary}

The perception that arises from the Eleventh Amendment of the Special Education law which was enacted in Israel in 2018 emphasizes the budgeting of the services the SwSN is eligible to receive according to a standard assessment of his functioning (in addition to the reference to the type of disability) and his "Parents' Choice" of his placement. ${ }^{42}$ The implementation of this perception was examined in one school of special education as a test case that sharpens the importance of the implementation of educational processes centered on the students' needs, which are examined professionally and measurably and from a broad view of the various life circles of the SwSN, through the sharing and involvement of his parents in the performed educational processes. It is possible to see this as an extension of the "Parents' Choice" principle - from the choice of the educational framework to parents' involvement in processes related to their child.

The use of exists tool for measurable assessment, which is an available and useful for the teachers, enabled immediate and uncomplicated analysis of the findings, and accordingly work on three levels: the level of the individual student, the level of the class, and the level of the school. The work process was characterized by the transition from work based, partly, on intuition and impression to professional data-based work, by the transition to a long-term process approach, and by the transition from a "closed" work inside school to openness characterized by partnership and involvement of the parents. These were expressed in the focus on the individual -

42 The Special Education Law, 2018. 
the building of tailored personal plans in the ADL field and the follow up after the student's progress and the providing a relevant and ongoing answer to his needs. On the class level, the assessment enabled mapping of the classes in the ADL field and the planning of adjusted class programs. In the systemic aspect, the work according to the ADL assessment enabled an overview on the school conduct on the topic of the "preparation for life", focus on the curriculum on this topic, and identification of the needs when allocating resources. In addition, the process focused on the identification of the school staff needs for professional development and appointment of roleholders for leading the ADL field in the school. The tool helped the homeroom teachers direct the parents for the work continuation with their children according to data-based assessment and reinforced the partnership with them and their involvement in the process of their children's progress.

The presented case study is a single case of a special education school. It is necessary to broaden the examination of the implementation of Amendment 11 of the Special Education Law perception in additional special education schools and in additional frameworks special education classes in general schools and in the inclusion framework, and in additional aspects and areas in the educational field. And most importantly, examine the implementation of Amendment 11 of the Special Education Law from the central aspect of its legislation - the inclusion of SwSNs in general education.

\section{Bibliography}

[1] Avissar G., Inclusion and accessibility: Curriculum planning and implementation for students with disabilities, Mofet Institute, Tel Aviv, 2010. [Hebrew]

[2] Avissar G., Bab Ts., Processes and trends in the planning of the studies in Israel for students with disabilities, Theory and Practice in the Planning of the Studies, 2010, 21. [Hebrew]

[3] Avissar G., Moshe A., Licht P., "These are basic democratic values": The perceptions of policy makers in the Ministry of Education with regard to inclusion, [in:] Inclusiveness: From theory to practice, eds S. Reiter, G. Avissar, AHVA Publishers, Haifa, 2013. [Hebrew] 
[4] "Assif", a collection kit for the "transition" program for special needs students studying in special education frameworks, ages 16-21, Ministry of Education, Special Education Department, 2012. [Hebrew]

[5] Blass N., Laor A., Special education in Israel and the policy of inclusion. The Center for the Research of Social Policy in Israel Press, Jerusalem 2002. [Hebrew]

[6] Crockett J.B., Kauffman J.M., The least restrictive environment. Lawrence Erlbaum, New Jersey 1999.

[7] Dorner Committee, Report of the Public Committee for the Examination of the Special Education System in Israel, Ministry of Education, Jerusalem, 2009. [Hebrew]

[8] Harpaz Y., Every Student Is a Student with Special Needs, Hed Hahinuch, Echo of Education, 2013, 87(6). [Hebrew]

[9] Howard P., The Least Restrictive Environment: How to tell, Journal of Law \& Education, 2004, 33.

[10] Margalit Committee, Report of the Committee for the Examination of the Realization of the Ability of Students with Learning Disabilities. Ministry of Education, Culture, and Sport, Department of Special Education, Jerusalem 1997. [Hebrew]

[11] Margalit Committee, Report of the Committee for the Examination of the Implementation of the Special Education Law, Ministry of Education, Jerusalem 2000. [Hebrew]

[12] Marom M., Bar-Simon Tov K., Kron A., Koren P., Inclusion of special needs children in the regular educational system: A review of the literature, The Center for the Research of Social Policy in Israel Press, Jerusalem 2006. [Hebrew]

[13] Neon D., Milshtein M., Marom M., Integration of children with special needs in the elementary schools: Follow up after the implementation of the 'Book of Inclusion' in the Special Education Law. The Center for the Research of Disabilities and Employment of Special Populations, Jerusalem 2012. [Hebrew]

[14] Nirje B., The basis and logic of the normalization principle, Australia and New Zealand Journal of Developmental Disabilities, 1985, 11(2).

[15] Project protocol WHO and WFOT, Quality assurance project concerning CVApatients, Denmark: The Danish Occupational Therapy Association (1992).

[16] Reiter S., Schanin M., Tirosh E., Israeli elementary school students' and teachers' attitudes towards mainstreaming children with disabilities, Special Services in the Schools, 1998, 13(1/2).

[17] Robson C., Students with disabilities, learning difficulties and disadvantages: statistics and indicators. OECD: Organisation for Economic Cooperation and Development, France 2005, 20. ISBN 9264009809.

[18] Ronen H., The future of the special school, Issues in Special Education and Rehabilitation, 2003, 18(1). [Hebrew]

[19] Ronen H., Inclusion: Issues and disputes, [in:] Inclusiveness: Learners with disabilities in education, eds S. Reiter, Y. Leyser, G. Avissar, AHVA Publishers, Haifa, 2007. [Hebrew] 
[20] Sachs D., Schreuer N., Adato-Biram I., Academic, physical and human support to promote participation of people with disabilities in higher education, Paper presented at the conference of Council of Occupational Therapists in European Countrives (COTEC), Hamburg, Germany, May 2008.

[21] Sachs D., Yaakobi-Vekert R., Zussman N., A survey of treatment frameworks, methods and assessment methods and treatment which are customary in occupational therapy with patients after a stroke, Israeli Journal of Occupational Therapy, 1995, $\mathrm{H} 147-\mathrm{H} 127,4(4)$.

[22] The Special Education Law, 5748, State of Israel, 1988. [Hebrew]

[23] The Special Education Law 5762 (Amendment No. 7), State of Israel, 2002. [Hebrew]

[24] The Special Education Law 2734 (Amendment No. 11), State of Israel, 2018. [Hebrew]

[25] Students with Disabilities, Learning Difficulties and Disadvantages Policies: Statistics and Indicators OECD: Organization for Economic Cooperation and Development, 2007, 30. ISBN 978-92-64-02762-6. 